\title{
DNA Methylation and Histone Modifications Are the Molecular Lock in Lentivirally Transduced Hematopoietic Progenitor Cells
}

\author{
Siew Ching Ngai, ${ }^{1,2}$ Rozita Rosli, ${ }^{1,3}$ Akram Al Abbar, ${ }^{1,3}$ and Syahril Abdullah ${ }^{1,3}$ \\ ${ }^{1}$ Medical Genetics Laboratory, Clinical Genetics Unit, Faculty of Medicine and Health Sciences, UPM, \\ 43400 Serdang, Selangor, Malaysia \\ ${ }^{2}$ School of Biosciences, Faculty of Science, The University of Nottingham Malaysia, Jalan Broga, 43500 Semenyih, Selangor, Malaysia \\ ${ }^{3}$ Genetics \& Regenerative Medicine Research Centre, Faculty of Medicine and Health Sciences, UPM, \\ 43400 Serdang, Selangor, Malaysia
}

Correspondence should be addressed to Syahril Abdullah; syahril@upm.edu.my

Received 5 January 2015; Revised 2 March 2015; Accepted 4 March 2015

Academic Editor: Yujungeorge Zheng

Copyright (C) 2015 Siew Ching Ngai et al. This is an open access article distributed under the Creative Commons Attribution License, which permits unrestricted use, distribution, and reproduction in any medium, provided the original work is properly cited.

\begin{abstract}
Stable introduction of a functional gene in hematopoietic progenitor cells (HPCs) has appeared to be an alternative approach to correct genetically linked blood diseases. However, it is still unclear whether lentiviral vector (LV) is subjected to gene silencing in HPCs. Here, we show that LV carrying green fluorescent protein (GFP) reporter gene driven by cytomegalovirus (CMV) promoter was subjected to transgene silencing after transduction into HPCs. This phenomenon was not due to the deletion of proviral copy number. Study using DNA demethylating agent and histone deacetylase (HDAC) inhibitor showed that the drugs could either prevent or reverse the silencing effect. Using sodium bisulfite sequencing and chromatin immunoprecipitation (ChIP) assay, we demonstrated that DNA methylation occurred soon after LV transduction. At the highest level of gene expression, CMV promoter was acetylated and was in a euchromatin state, while GFP reporter gene was acetylated but was strangely in a heterochromatin state. When the expression declined, CMV promoter underwent transition from acetylated and euchromatic state to a heterochromatic state, while the GFP reporter gene was in deacetylated and heterochromatic state. With these, we verify that DNA methylation and dynamic histone modifications lead to transgene silencing in HPCs transduced with LV.
\end{abstract}

\section{Introduction}

Gene therapy is the introduction of therapeutic genes into target cells to treat a disease or medical disorder [1]. Successful gene therapy requires specific, efficient, stable, and high levels of gene transfer into the target cells in order to achieve the therapeutic effects. Hematopoietic progenitor cells (HPCs) are attractive target cells for many blood diseases such as $\beta$-thalassemia and sickle cell disease as well as other hematological malignancies due to their ability to selfrenew and reconstitute all lineages in the hematolymphoid system [2]. Lentiviral vectors (LVs) are promising tools in gene therapy for hematological diseases because they can efficiently transduce HPCs, which are quiescent and difficult to target [3].
However, several literatures have reported a decline in transgene expression in early progenitor cells and stem cells transduced with LVs over time in murine embryonic carcinoma P19 cells, human bladder carcinoma T24 cells, human breast carcinoma MDA-MB-231 cells, and others [4, 5]. Epigenetic effects were found as the confounding factor for the transgene expression decline in several cell types [47]. The epigenetic mechanisms, which have been proposed as the factors for transgene silencing, are DNA methylation, histone modifications, and microRNAs [8,9]. Although studies on epigenetic effects on transgene expression have been performed on different cell types [4-7], none have been conducted on HPCs transduced by LV.

Therefore, in this study, we seek to (i) determine the gene expression profiles in HPCs transduced with LV and 
to (ii) examine whether DNA methylation and histone deacetylation are the factors for gene silencing in LV gene delivery. Identification and understanding of the factors for gene silencing could lead to the efforts in preventing the silencing effects in HPCs transduced with LVs. The extended expression of therapeutic gene in HPCs would lead to an efficient gene therapy to hereditary blood diseases with a single or periodic dosing.

\section{Methodology}

2.1. Isolation, Purification, Verification, and Enrichment of HPCs. Bone marrow cells were flushed from femur and tibia of $\mathrm{BALB} / \mathrm{c}$ mice using recommended medium (phosphate buffered saline (PBS) $+2 \%$ fetal bovine serum (FBS) $+1 \mathrm{mM}$ ethylenediaminetetraacetic acid) with a syringe equipped with a 23-gauge needle into a $100 \mathrm{~mm}$ diameter tissue culture plate. This step was repeated several times to flush all of the bone marrow cells out from the marrow cavities. Clumps were dispersed by gently passing the cell suspension through the syringe repeatedly. The cells were transferred into a $15 \mathrm{~mL}$ centrifuge tube. The cells were centrifuged at $250 \times \mathrm{g}$ for 5 minutes at $4^{\circ} \mathrm{C}$. Then, the supernatant was discarded and the cell pellet was resuspended in $1 \mathrm{~mL}$ of recommended medium with $2 \%$ normal rat serum. The amount of the cells was counted and then prepared at a concentration of $1 \times 10^{8}$ cells $/ \mathrm{mL}$ in a $5 \mathrm{~mL}$ polystyrene tube. The cells were subjected to Lin negative selection step, followed by cKit positive selection step by EasySep Magnetic Nanoparticles Separation (StemCell Technologies, Inc., Vancouver, BC, Canada) according to the manufacturer's instructions. The purified $\mathrm{Lin}^{-} \mathrm{cKit}^{+}$cells were verified by flow cytometry analysis and the fold of cells enrichment was determined.

2.2. Duration of Transgene Expression. Viral transduction of purified HPCs was performed using Stemspan, SFM medium supplemented with $100 \mathrm{ng} / \mathrm{mL}$ recombinant human interleukin-11, $100 \mathrm{ng} / \mathrm{mL}$ human FMS-like tyrosine kinase 3 ligand, $50 \mathrm{ng} / \mathrm{mL}$ recombinant murine stem cell factor (Stemcells Technologies), and $40 \mu \mathrm{g} / \mathrm{mL}$ lipoprotein low density from human plasma (Sigma Aldrich). HPCs were plated at 5 $\times 10^{4}$ cells/well in a 24 -well plate. HPCs were transduced with LV carrying green fluorescent protein (GFP) reporter gene with the multiplicity of infection (MOI) of 3.2 (Optimal MOI, results not shown) in the presence of Polybrene $(6 \mu \mathrm{g} / \mathrm{mL})$. LV-containing medium was discarded and replaced with fresh complete culture medium at day 1 after transduction. The GFP expression was measured at 6 hours and at days 1, 2, 3,5 , and 7 after transduction using flow cytometry. The results were evaluated as the percentage of GFP positive cells within total events acquired at different time points.

2.3. Relative Transgene Copy Number. LV-transduced HPCs and untreated HPCs were prepared following the protocol described above. The cells were harvested at day 2 and day 7 after transduction. DNA was extracted from $1 \times 10^{5}$ cells using DNeasy Blood and Tissue kit (Qiagen). The concentration and the purity of DNA were determined by Nanodrop 2000
(Thermo Scientific, Wilmington, DE). The samples were subjected to polymerase chain reaction (PCR) with GoTaq DNA polymerase (Promega) in the provided GoTaq Flexi buffer under the following conditions: (i) for hypoxanthineguanine phosphoribosyltransferase (HPRT) gene: $95^{\circ} \mathrm{C}$ for 2 minutes, followed by 35 cycles of $95^{\circ} \mathrm{C}$ for 1 minute, $56.6^{\circ} \mathrm{C}$ for 1 minute, and $72^{\circ} \mathrm{C}$ for 1 minute, with a final extension at $72^{\circ} \mathrm{C}$ for 5 minutes; (ii) for transgene: $95^{\circ} \mathrm{C}$ for 2 minutes, followed by 35 cycles of $95^{\circ} \mathrm{C}$ for 1 minute, $47^{\circ} \mathrm{C}$ for 1 minute, and $72^{\circ} \mathrm{C}$ for 1 minute, with a final extension at $72^{\circ} \mathrm{C}$ for 5 minutes. The PCR primers were $5^{\prime}$ HPRT gene, $5^{\prime}$-GCTGGTGAAAAGGACCTCT-3'; $3^{\prime}$ HPRT gene, $5^{\prime}$-CACAGGACTAGAACACCTGC- $3^{\prime} ; 5^{\prime}$ transgene, $5^{\prime}$-ATAAGCTTGGGAGTTCCGCG-3'; $3^{\prime}$ transgene, $5^{\prime}$ AAAGCTGGGTTTACTTGTACAG- $3^{\prime}$. The PCR products were subjected to agarose gel electrophoresis at 75 volts for 40 minutes. The intensity of the band was determined by Fluorchem FC2 system (Alpha Innotech Corporation, USA).

2.4. Cells Treatment with 5-Azacytidine and Trichostatin A. HPCs were transduced with LV as described above. To prevent the silencing, different concentrations of 5-azacytidine (5-azaC) $(1,2,5$, and $10 \mu \mathrm{M})$ were added to the medium the following day of transduction. To reverse the silencing, different concentrations of 5 -azaC $(1,2,5$, and $10 \mu \mathrm{M})$ were added on the day of transgene silencing (day 3 after transduction). On the following day of 5-azaC treatment, 5-azaC-containing medium was discarded and replaced with fresh complete medium. At day 5 after transduction, the cells were harvested and centrifuged at $250 \times \mathrm{g}$ for 5 minutes. The supernatant was discarded and the cell pellet was resuspended in PBS containing $1 \%$ FBS.

The experimental protocol was repeated for the study of Trichostatin A (TSA) at different concentrations (50, 100, and $150 \mathrm{nM})$ and the combination of 5-azaC and TSA at different concentrations $(2 \mu \mathrm{M} 5$-azaC $+50 \mathrm{nM}$ TSA and $2 \mu \mathrm{M} 5$-azaC $+150 \mathrm{nM}$ TSA). The cells were dissociated and centrifuged at $250 \times \mathrm{g}$ for 5 minutes to remove residual media components. Next, the cell pellet was resuspended in PBS containing 1\% FBS. Total event of 10,000 was set. The cells were analyzed for green fluorescence by FACSvantage (Becton Dickinson, San Jose, CA) using CellQuest software. Dead cells were excluded and negative green fluorescence was set at around $1 \%$ for the untreated cells.

2.5. Sodium Bisulfite Genome Sequencing. The transduced cells were harvested at day 2 and day 7 after transduction. DNA was extracted from $1 \times 10^{5}$ cells using DNeasy Blood and Tissue kit (Qiagen) following the manufacturer's instructions. The concentration and the purity of DNA were determined by Nanodrop 2000 (Thermo Scientific, Wilmington, DE).

Methylated $\mathrm{pL} / \mathrm{CMV} / \mathrm{GFP}(1 \mu \mathrm{g})$ (served as the positive control) and the genomic DNA $(1 \mu \mathrm{g})$ from the transduced cells harvested at day 2 and day 7 after transduction were subjected to restriction enzyme digestion prior to bisulfite conversion. All the samples were digested with $10 \mathrm{U}$ of EcoR1 and AvaI in $1 \times$ NE buffer 4 in a total reaction volume of $50 \mu \mathrm{L}$. The reaction mixture was incubated at $37^{\circ} \mathrm{C}$ for 1 hour. The restriction digested DNA was purified from the enzymatic 
reaction by using MinElute Reaction Cleanup Kit (Qiagen). The DNA fragments between $70 \mathrm{bp}$ and $4 \mathrm{~kb}$ were purified. The purified DNA was chemically treated with sodium bisulfite mix $(85 \mu \mathrm{L})$ and then purified by using EpiTect Bisulfite Kit (Qiagen). The purified DNA from bisulfite conversion reaction was subjected to PCR with GoTaq DNA polymerase (Promega) in the provided GoTaq Flexi buffer under the following conditions: $95^{\circ} \mathrm{C}$ for 2 minutes, followed by 35 cycles of $95^{\circ} \mathrm{C}$ for 1 minute, $52.9^{\circ} \mathrm{C}$ for 1 minute, and $72^{\circ} \mathrm{C}$ for 1 minute, with a final extension at $72^{\circ} \mathrm{C}$ for 5 minutes. The PCR primers targeting $\mathrm{CMV}$ promoter region were as follows: $5^{\prime}$ CMV promoter, 5' -ATAAGCTTGGGAGTTCCGCG-3'; $3^{\prime}$ CMV promoter, $5^{\prime}$-CCTCTAGAGTCGGTGTCTTCT-3'. PCR product was verified by agarose gel electrophoresis. The bands were visualized by Fluorchem FC2 system (Alpha Innotech Corporation, USA). The fresh verified PCR products were cloned into pCR 2.1-TOPO by TOPO TA Cloning Kit (Invitrogen) and transformed into JM109 competent cells on the same day. The inoculum was subjected to DNA purification using PureLink HQ Mini Plasmid Purification Kit. The purified DNA was subjected to sequencing by using pCR 2.1-TOPO M13 reverse primer.

2.6. Chromatin Immunoprecipitation Assay. The transduced HPCs were harvested at day 2 and day 7 after transduction. The cells were subjected to ChIP assay by using ChIP Kit (Abcam, Inc., Cambridge, MA). The chromatins were labelled with (i) anti-histone $\mathrm{H} 3$ acetyl K9 (anti-H3K9) antibody (ab10812; Abcam), (ii) anti-histone H3 dimethyl lysine 4 (anti-H3 diMeK4) antibody (ab32356; Abcam), (iii) antihistone H3 dimethyl lysine 9 (anti-H3 diMeK9) antibody (ab1220; Abcam), and (iv) negative control (Beads only), respectively. Anti-H3K9 antibody was used to detect $\mathrm{H} 3$ acetylation; anti-H3 diMeK4 antibody is a marker for euchromatin; anti-H3 diMeK9 antibody is a marker for heterochromatin. The samples were incubated overnight with rotation at $4^{\circ} \mathrm{C}$. To pull down antibody-DNA-protein, $50 \mu \mathrm{L}$ of DNA purifying slurry was added to the samples. The samples were mixed by inversion and incubated at $98^{\circ} \mathrm{C}$ for 10 minutes. After incubation, the samples were left at room temperature for 20 minutes to cool. Proteinase $\mathrm{K}(1 \mu \mathrm{L})$ was added to the samples and then vortexed for 5 seconds at medium power. The samples were incubated at 30 minutes at $55^{\circ} \mathrm{C}$ and then 10 minutes at $98^{\circ} \mathrm{C}$. DNA slurry was pelleted by centrifugation at $14000 \times \mathrm{g}$ for 1 minute at room temperature. The supernatant was transferred to a clean $1.5 \mathrm{~mL}$ tube. PCRgrade $\mathrm{H}_{2} \mathrm{O}(65 \mu \mathrm{L})$ was added to the DNA slurry and then vortexed for 10 seconds at medium power. DNA slurry was pelleted by centrifugation at $14000 \times \mathrm{g}$ for 1 minute at $4^{\circ} \mathrm{C}$ and the supernatant was transferred to a clean $1.5 \mathrm{~mL}$ tube. The purified DNA after ChIP assay was subjected to PCR with GoTaq DNA polymerase (Promega) in the provided GoTaq Flexi buffer under the following conditions: (i) $\beta$ actin promoter: $95^{\circ} \mathrm{C}$ for 2 minutes, followed by 35 cycles of $95^{\circ} \mathrm{C}$ for 1 minute, $54.7^{\circ} \mathrm{C}$ for 1 minute, and $72^{\circ} \mathrm{C}$ for 1 minute, with a final extension at $72^{\circ} \mathrm{C}$ for 5 minutes; (ii) $\mathrm{CMV}$ promoter: $95^{\circ} \mathrm{C}$ for 2 minutes, followed by 35 cycles of $95^{\circ} \mathrm{C}$ for 1 minute, $52.9^{\circ} \mathrm{C}$ for 1 minute, and $72^{\circ} \mathrm{C}$ for 1 minute, with a final extension at $72^{\circ} \mathrm{C}$ for 5 minutes; (iii) GFP gene: $95^{\circ} \mathrm{C}$ for
2 minutes, followed by 35 cycles of $95^{\circ} \mathrm{C}$ for 1 minute, $47^{\circ} \mathrm{C}$ for 1 minute, and $72^{\circ} \mathrm{C}$ for 1 minute, with a final extension at $72^{\circ} \mathrm{C}$ for 5 minutes. The PCR primers used were $5^{\prime} \beta$-actin promoter, $5^{\prime}$-ATGCTGCACTGTGCGGCGAG- $3^{\prime} ; 3^{\prime} \beta$-actin promoter, $5^{\prime}$-TGGCTGCAAAGAGTCTACACG- $3^{\prime} ; 5^{\prime} \mathrm{CMV}$ promoter, $5^{\prime}$-ATAAGCTTGGGAGTTCCGCG-3'; $3^{\prime}$ CMV promoter, $5^{\prime}$-CCTCTAGAGTCGGTGTCTTCT-3 ${ }^{\prime} ; 5^{\prime}$ GFP gene, $5^{\prime}$-CTCCACCATGGTGAGCAA- $3^{\prime} ; 3^{\prime}$ GFP gene, $5^{\prime}$ AAAGCTGGGTTTACTTGTACAG- $3^{\prime}$. The PCR products were verified by agarose gel electrophoresis at 75 volts for 40 minutes. The bands were visualized by Fluorchem FC2 system.

2.7. Statistical Analysis. Numerical data was expressed as mean with standard deviations. ANOVA was applied to compare the means of the experiment samples, followed by Post hoc test to determine the statistical significance in the mean difference. Differences of $P<0.050$ were considered statistically significant.

\section{Results and Discussion}

3.1. Isolation, Purification, Verification, and Enrichment of HPCs. The hallmark of HSCs is their lifelong reconstitution of the multilineage hematopoiesis potential in the transplanted hosts. Identification and isolation of such cells have challenged researchers for decades [10]. Up to date, the primitive HSCs of adult murine bone marrow are isolated by $\mathrm{Lin}^{-} \mathrm{Sca}^{+} \mathrm{cKit}^{+}$selection [11]. However, Sca-1 expression on HSCs is variable in different mouse strains [12]. The expression of Sca-1 in BALB/c mouse is lower compared to C57BL/6J mouse. The use of Sca-1 in HSCs isolation from $\mathrm{BALB} / \mathrm{c}$ mice will reduce the amount of the purified HSCs because many of the primitive HSCs, which do not express Sca-1, will be lost during the isolation step. Therefore, we selected $\mathrm{Lin}^{-} \mathrm{cKit}^{+}$instead of using the $\mathrm{Lin}^{-} \mathrm{Sca}^{+} \mathrm{CKit}^{+}$for the cells isolation from $\mathrm{BALB} / \mathrm{c}$ mouse and the isolated cells are termed HPCs.

Before the isolation by using EasySep Magnetic Cell Separation, the percentage of $\mathrm{Lin}^{-} \mathrm{CKit}^{+}$cells was $2.20 \%$, verified by flow cytometry analysis. After the isolation steps, the percentage of $\mathrm{Lin}^{-} \mathrm{cKit}^{+}$cells was $93.35 \%$. The results of flow cytometry analysis are shown in Figure 1. The enrichment of HPCs was 42-fold. The HPCs isolated were highly enriched. Therefore, this separation method had successfully depleted most of the unwanted cells and enriched the murine HPCs prior to experimental steps.

3.2. Duration of the Transgene Expression in HPCs. The transduction efficiency and duration of transgene expression of HPCs transduced with LV were examined in vitro. The GFP expression was determined at 6 hours and at days $1,2,3,5$, and 7 after transduction. Figure 2 shows rapid transgene silencing in HPCs transduced with the LV. The GFP expression increased from $1.57 \%$ at 6 hours to $7.34 \%$ at day 1 after transduction. The highest level of transgene expression was read at day 2 after transduction $(17.08 \%)(P<$ 0.001). The GFP expression decreased starting from day 2 after transduction, reaching values of $4.07 \%$ at day 7 after 

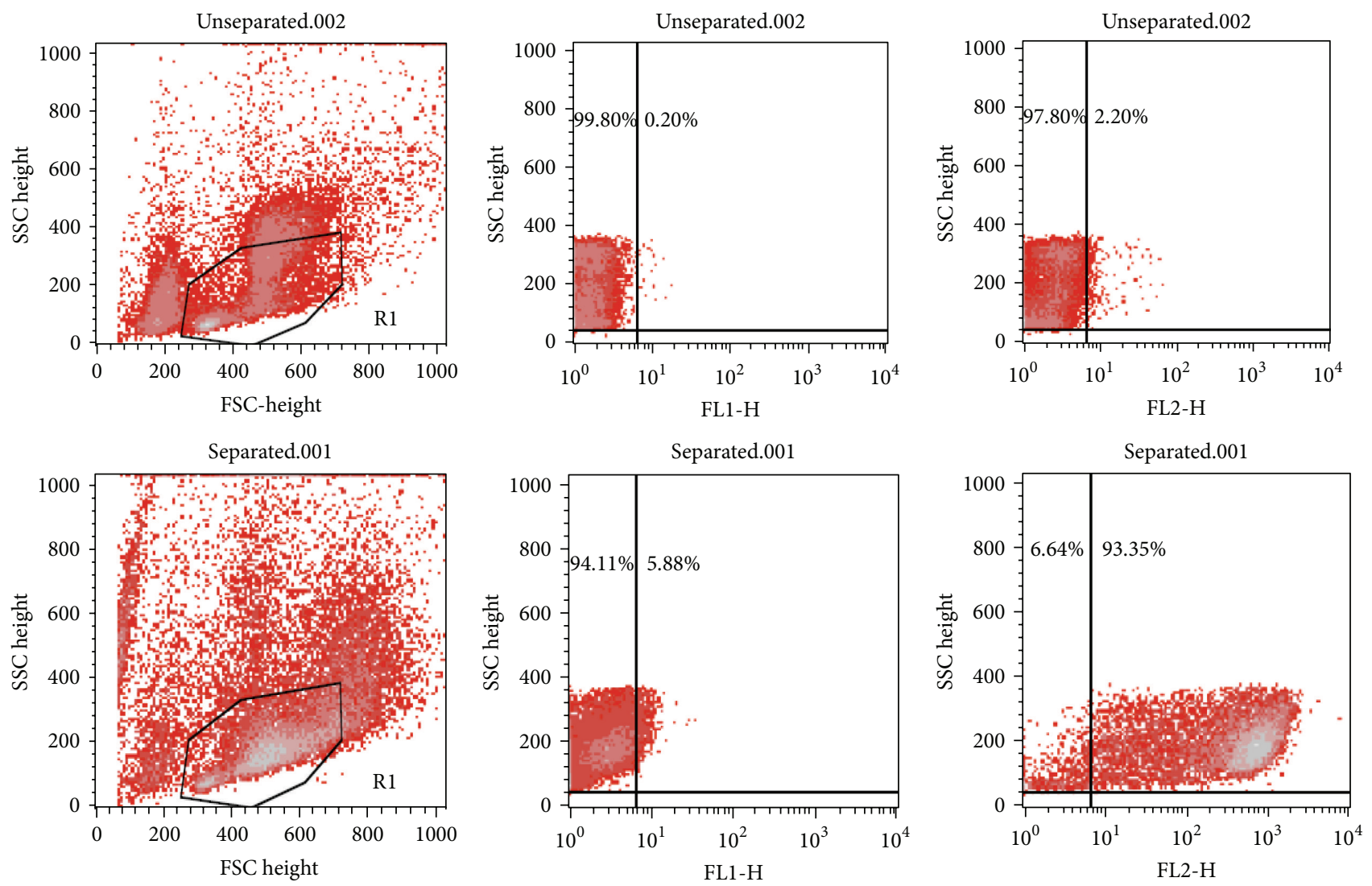

FIgURE 1: The verification of the isolated $\mathrm{Lin}^{-} \mathrm{cKit}{ }^{+}$cells by flow cytometry analysis. Before HPC purification, the percentage of HPCs was 2.20. After purification, the percentage of HPCs was 93.35.

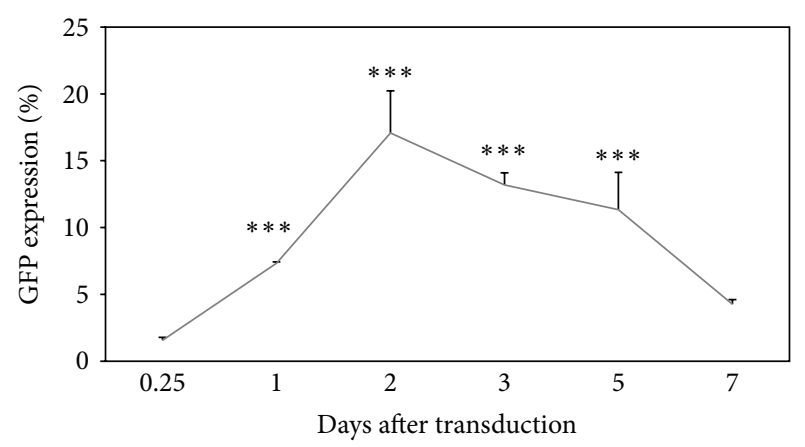

FIGURE 2: GFP expression of HPCs transduced with LV/CMV/GFP at MOI of 3.2 at different time points. The GFP expression was measured, at days 0.25 (6 hours), 1, 2, 3, 5, and 7 after transduction as the percentage of GFP-expressing cells within the total events acquired. Data are presented as mean \pm standard deviation in triplicate. Statistical difference between groups compared to the untreated group is reported as ${ }^{* * *} P<0.001$.

transduction $(P<0.001)$. LV transgene silencing was also observed in many cell types although the rate of silencing varies depending on the cell types $[4,13,14]$. Since the GFP expression started to decrease at day 2 after transduction, therefore, day 3 was chosen as the day of transgene silencing for the following experiments.
3.3. Relative Transgene Copy Number. To exclude the contribution of the loss of the integrated provirus to the transient gene expression, the genomic DNA was extracted from the untransduced cells and transduced cells at day 2 and day 7 after transduction. The extracted genomic DNA was subjected to PCR with the primers specific to the proviral transgene and with the primers specific to HPRT gene as a control.

Figure 3 shows that the expected bands were obtained in Lanes 2, 3, and 4 which were set as the controls, indicating that the mouse housekeeping HPRT gene was expressed in both untransduced and transduced murine HPCs harvested at day 2 and day 7 after transduction. No band was obtained in Lane 5, which was set as negative control for PCR. For PCR with primers specific to the transgene, no band was obtained for the untransduced cells (Lane 6), indicating no integrated provirus in the cells. Expected bands were obtained for the LV-transduced cells harvested at day 2 and day 7 after transduction, indicating that the provirus was integrated into the cells genome. No band was obtained for PCR reaction mixture without DNA, which was set as negative control.

The relative transgene copy number was determined by dividing the band intensity of HPRT gene with band intensity of transgene at day 2 and day 7 after transduction, respectively. The gene copy number of HPRT gene was set as 2 and the relative transgene copy numbers for the transduced cells were 0.62 at day 2 and 0.92 at day 7 after 


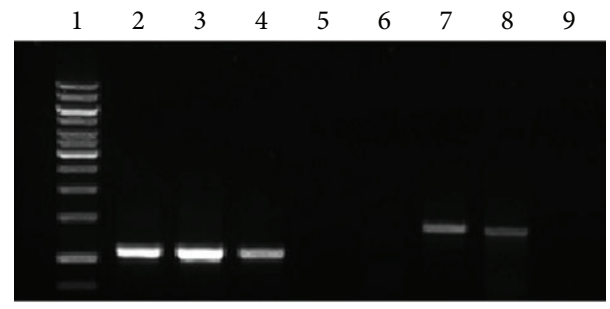

FIgURE 3: Relative transgene copy number. The extracted genomic DNA from the transduced cells at day 2 and 7 after transduction was subjected to PCR to amplify the transgene region of the sample. Lane 1: $1 \mathrm{~kb}$ ladder; Lanes 2-4: PCR with primers specific for HPRT gene; Lane 2: Untransduced genomic DNA (positive control for PCR); Lane 3: transduced genomic DNA extracted at day 2 after transduction (positive control for relative transgene copy number); Lane 4: transduced genomic DNA extracted at day 7 after transduction (positive control for relative transgene copy number); Lane 5: PCR reaction without DNA (negative control); Lane 69: PCR with primers specific to transgene; Lane 6: untransduced genomic DNA; Lane 7: transduced genomic DNA extracted at day 2 after transduction; Lane 8: transduced genomic DNA extracted at day 7 after transduction; Lane 9: PCR reaction without DNA (negative control for PCR).

transduction. This shows that the relative provirus DNA copy number remained almost the same. Therefore, we believe that the transgene silencing was caused by certain silencing machineries and not due to the loss of proviral DNA. This is consistent with the results shown by $\mathrm{He}$ et al. [4], in which the decrease of transgene expression by LV at the very early stage after gene transfer was due to transcriptional silencing in murine embryonic carcinoma P19 cells and not due to the deletion of the transgene. Besides that, our results were further supported by other research groups which reported that the primary mechanism that limits the longterm episomal expression is caused by gene silencing, rather than loss of vector DNA $[15,16]$. Following this, we further investigated the factors of transgene silencing in the following experiments.

\subsection{DNA Methylation as the Factor for Transgene Silencing.} As 5 -azaC is a demethylating agent, its effect on the prevention of transgene silencing and reversion of a silenced gene may implicate DNA methylation as the cause for the short-lived transgene expression. HPCs were transduced with $\mathrm{LV}$ and the LV-containing medium was discarded at day 1 after transduction. 5-azaC was added on the day after the LV transduction to prevent the transgene silencing (prevention study) or on the day of transgene silencing to reverse the silenced gene (reversion study). Based on the results obtained shown in Figure 4, 5-azaC was able to prevent and reverse the silencing effect in a dose-dependent manner. In the reversion study, the GFP expression was $17.37 \%, 20.52 \%, 32.22 \%$, and $44.48 \%$ for the cells treated with $1,2,5$, and $10 \mu \mathrm{M} 5$-azaC. The GFP expression was $15.70 \%, 21.50 \%, 27.70 \%$, and $53.31 \%$, respectively, for $1,2,5$, and $10 \mu \mathrm{M}$ of 5 -azaC added to prevent the silencing effects. The cells treated with 5 -azaC at different concentrations for both prevention and reversion studies

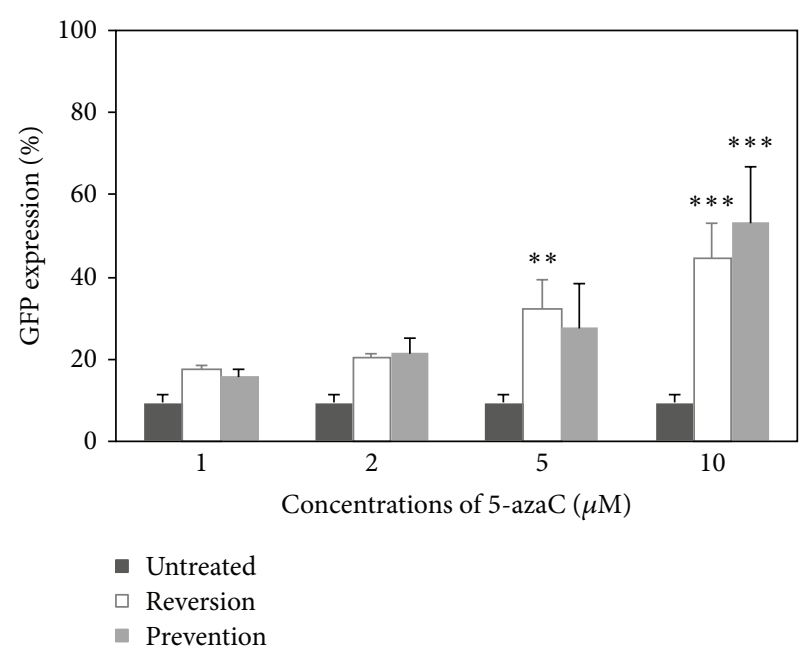

FIGURE 4: GFP expression of HPCs transduced with LV/CMV/GFP and treated with $1,2,5$, and $10 \mu \mathrm{M} 5$-azaC to prevent and to reverse GFP silencing. The expression was measured at day 5 after transduction. Untreated cells were served as the control. Data are presented as mean \pm standard deviation in triplicate. Statistical difference between groups compared to the transduced untreated group is reported as ${ }^{* *} P<0.010$ and ${ }^{* * *} P<0.001$.

showed a trend of higher GFP expression when compared to the transduced 5-azaC-untreated cells (9.27\%). However, not all the values were statistically significant.

Based on the results obtained, 5-azaC could prevent and reverse DNA methylation in a dose-dependent manner. Our results on the prevention study corroborates the study by Escher et al. [17], which showed that 5-azaC prevented the methylation of the CMV promoter in the transfected murine macrophage RAW 264.7 cells. Besides that, Di Ianni et al. [18] reported that the 5-azaC prevented transgene methylation in severe combined immunodeficiency disease mice injected with herpes simplex virus type 1 thymidine kinase gene/bacterial beta-galactosidase gene- (LacZ-) transduced human monocytic U937 cells. 5-azaC was found to integrate into the DNA and prevent methylation by inhibiting Dnmt [19]. For the reversion study, our results substantiate the study by $\mathrm{Ou}$ et al. [5] who reported that methylated genes could be restored by 5 -azaC. In addition, He et al. [4] also demonstrated that 5 -azaC was able to reactivate the $L a c Z$ expression in a dose-dependent manner in murine embryonic carcinoma P19 cells transduced with LV. These are in agreement with $\mathrm{Lu}$ and Richardson [20] who reported that 5-azaC could covalently bind to Dnmt and thus deplete cellular Dnmt pools, resulting in the hypomethylation of the nascent DNA strand.

3.5. Histone Deacetylation as the Factor for Transgene Silencing. Besides DNA methylation, histone acetylation and deacetylation have been shown to determine the transcriptional activity of the chromatin [21]. HDAC and other corepressor proteins are recruited by MBD or MECP2 to the methylated region of DNA to repress the transcription in a methylation-dependent manner [22]. The effect of HDAC 


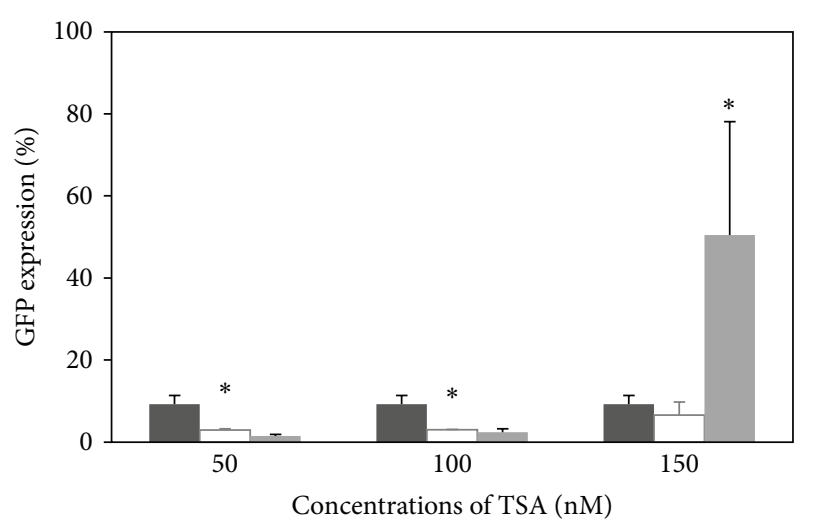

$\square$ Untreated
$\square$ Reversion
$\square$ Prevention

FIGURE 5: GFP expression of HPCs transduced with LV/CMV/GFP and treated with 50,100 , and $150 \mathrm{nM}$ TSA to prevent and to reverse GFP silencing. The expression was measured at day 5 after transduction. Untreated cells were served as the control. Data are presented as mean \pm standard deviation in triplicate. Statistical difference between groups compared to the transduced untreated group is reported as ${ }^{*} P<0.050$.

inhibitor, TSA, on the prevention of transgene silencing and reversion of a silenced gene was analyzed to examine whether histone deacetylation was associated with the shortlived transgene expression. TSA with different concentrations $(50,100$, and $150 \mathrm{nM})$ was added a day after transduction to prevent GFP silencing or on the day of transgene silencing to reverse the silenced GFP. The GFP expression was checked at day 5 after transduction.

The GFP expression of the transduced cells without TSA treatment was 9.27\% (Figure 5). For the reversion of transgene silencing study, the GFP expression was $2.91 \%$, $2.99 \%$, and $6.57 \%$ for the cells treated with 50,100 , and $150 \mathrm{nM}$ TSA, respectively. The GFP expression of the transduced cells treated with 50 and $100 \mathrm{nM}$ TSA was significantly lower compared to the transduced untreated cells $(P=0.015$ and $P=0.017$, resp.). There was no significant difference in GFP expression between the transduced untreated cells with the transduced cells treated with $150 \mathrm{nM}$ TSA $(P=0.373)$. The result shows that TSA was unable to reverse the silenced GFP. This may be because histone deacetylation process has already occurred on the day of transgene silencing. Therefore, the addition of TSA has no effect, as it could only act on the activity of HDAC.

For the prevention of transgene silencing study, the GFP expression was $1.48 \%$ and $2.37 \%$ for the cells treated with 50 and $100 \mathrm{nM}$ TSA, respectively, which were lower than the control transduced untreated cells. The GFP expression of the cells treated with $150 \mathrm{nM}$ TSA (50.43\%) was significantly higher than the transduced untreated cells and the transduced cells treated with 50 and $100 \mathrm{nM}$ TSA $(P<$ $0.050)$. It is speculated that the treatment of TSA before gene silencing could inhibit HDAC's activity and consequently generated higher GFP expression compared to the untreated

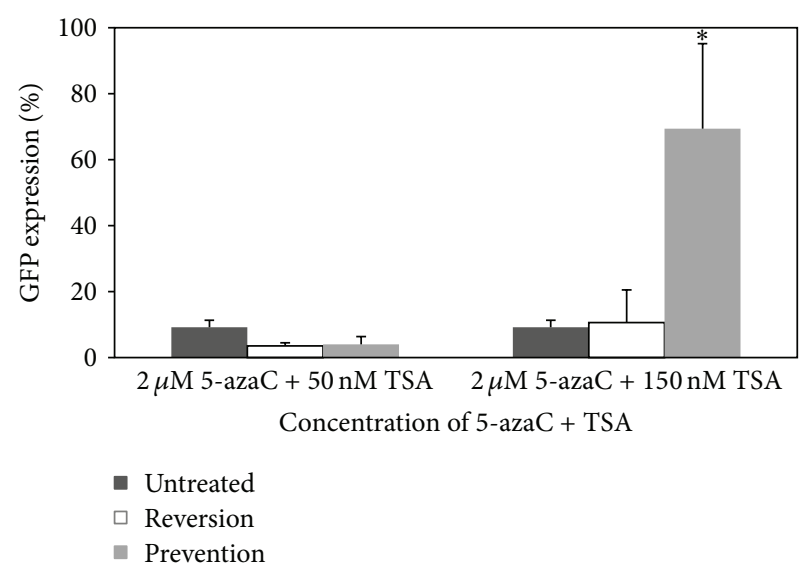

FIGURE 6: GFP expression of HPCs transduced with LV/CMV/GFP and treated either with $2 \mu \mathrm{M} 5$-azaC $+50 \mathrm{nM}$ TSA (Cocktail 1) or with $2 \mu \mathrm{M} 5$-azaC $+150 \mathrm{nM}$ TSA (Cocktail 2) to prevent and to reverse GFP silencing. The expression was measured at day 5 after transduction. Untreated cells were served as the control. Data are presented as mean \pm standard deviation in triplicate. Statistical difference between groups compared to the transduced untreated group is reported as ${ }^{*} P<0.050$.

cells. Since the histone deacetylation process is a balance of HDAC and HAT (histone acetyltransferase) activity, a decrease in TSA concentration can reduce histone acetylation and affects the transgene expression [5]. Therefore, there was no effect on GFP expression for the cells treated with lower concentrations of TSA ( $50 \mathrm{nM}$ and $100 \mathrm{nM}$ ).

3.6. DNA Methylation and Histone Deacetylation as the Factors for Transgene Silencing. It was reported that the reexpression of the silenced gene could be achieved in the presence of DNA demethylating agents and HDAC inhibitors [23]. Ou et al. [5] also reported that the drugs that affect the chromatin modifications would not affect the expression of methylated gene unless if they were used in combination with inhibitors of Dmnt. Furthermore, Ma et al. [24] reported that blockade of histone deacetylation by TSA prevents DNA methylation by decreasing its effect on Dnmtl expression.

Therefore, the effect of the combination of both drugs in preventing and reversing the transgene silencing was investigated after analyzing their individual effects. 5-azaC and TSA combinations (Cocktail 1: $2 \mu \mathrm{M}$ 5-azaC $+50 \mathrm{nM}$ TSA; Cocktail 2: $2 \mu \mathrm{M}$ 5-azaC + $150 \mathrm{nM}$ TSA) were added a day after transduction to prevent GFP silencing or on the day of GFP silencing to reverse the silenced GFP. The GFP expression in the reversion study was $3.56 \%$ and $10.67 \%$ for Cocktail 1 and Cocktail 2, respectively (Figure 6). Unfortunately, the readings were not statistically different from the transduced untreated cells (9.27\%). The GFP expression was low for the cells treated with Cocktail 1 in the prevention study. However, significantly high expression (70.00\%) was achieved for the transduced cells treated with Cocktail $2(P=0.006)$.

Based on the results obtained, our results further confirmed that the combination of 5-azaC and TSA could synergistically influence the GFP expression when the cells 
TABle 1: Percentage efficiency of CpG methylase and bisulfite conversion for positive control of sodium bisulfite sequencing.

\begin{tabular}{|c|c|c|c|c|}
\hline \multirow{2}{*}{ Reaction } & \multicolumn{3}{|c|}{ Efficiency (\%) } & \multirow{2}{*}{ Average (\%) } \\
\hline & Positive Control 1 & Positive Control 2 & Positive Control 3 & \\
\hline Efficiency of CpG methylase & 83.3 & 100 & 72.2 & 85.2 \\
\hline Efficiency of bisulfite conversion & 92.8 & 93.3 & 94.4 & 93.5 \\
\hline
\end{tabular}

were treated before the silencing occurred. On the reversion attempt of the silenced gene treated with the drug cocktails, our results demonstrated that when the HDACs and corepressors have already bound to the methylated DNA, the addition of the drug cocktails could not reverse the deacetylation process.

3.7. Sodium Bisulfite Sequencing. Partial reactivation of transgene expression by 5 -azaC suggests that DNA methylation plays some role in transgene silencing in murine embryonic carcinoma P19 cells [4]. Based on the results obtained, 5azaC was able to prevent and reverse the silencing effect. Therefore, we further examined the methylation status in CMV promoter region by sodium bisulfite sequencing. The unmethylated cytosine was converted to uracil after bisulfite treatment and read as thymine by sequencing, while the methylated cytosine residues remained unchanged.

As a positive control, CMV promoter of $\mathrm{pL} / \mathrm{CMV} / \mathrm{GFP}$ was methylated by $\mathrm{CpG}$ methylase in vitro (positive controls 1,2 , and 3). Based on the sequencing results obtained, CMV promoter region was methylated by $\mathrm{CpG}$ methylase successfully (Table 1). The CpG methylation efficiency by the methylase was up to $85.2 \%$ (methylated cytosine in $\mathrm{CpG} /$ totalCpG sites $\times 100 \%$ ). The other cytosine residues, which were not $\mathrm{CpG}$ motifs, were chemically converted to uracil by the bisulfite treatment. The efficiency of bisulfite conversion was $93.5 \%$ (amount of converted cytosine/amount of unmethylated cytosine $\times 100 \%$ ).

For the samples harvested at day 2 and day 7 after transduction, all the cytosine residues in the CpG motifs of the CMV promoter remained as cytosine, which means that all cytosine residues in the CpG sites were methylated (Figure 7). The result from day 7 sample 3 (thirdtriplicate for sample harvested at day 7 after transduction) was excluded as mutation occurred. There was no difference in the CMV promoter methylation pattern from the transduced cells harvested at day 2 and day 7 after transduction. The cytosine residues in the promoter region were found to be methylated as early as day 2 after transduction, during the peak of GFP expression. The methylation status was maintained until day 7 when the GFP expression declined. He et al. [4] reported that the packaging binding site plus packaging signal $(\mathrm{PBS}+\psi)$ region was heavily methylated when the transgene expression was high. In contrast, it was reported that the $\mathrm{CpG}$ methylation in the $\mathrm{EF} 1 \alpha$ promoter progresses gradually in accordance to the reduction in transgene expression. In this study, we used the EpiTect Bisulfite Kit (Qiagen) for bisulfite conversion, which is reputed to convert unmethylated cytosine to more than $90 \%$ efficiency. This claim has been substantiated by the result from Table 1 .

\begin{abstract}
Positive control 1:
Positive control 2:

Positive control 3:

(a) Methylases treated $\mathrm{pL} / \mathrm{CMV} / \mathrm{GFP}$ (positive control)

Sample 1:

Sample 2:

Sample 3:

(b) CMV promoter from HPCs harvested at day 2 after transduction

Sample 1:

Sample 2:

Sample 3:

Excluded

(c) CMV promoter from HPCs harvested at day 7 after transduction
\end{abstract}

FIGURE 7: Bisulfite genomic sequencing of $\mathrm{CpG}$ in the methylated CMV promoter region. (a) Methylase treated $\mathrm{pL} / \mathrm{CMV} / \mathrm{GFP}$ (positive control), (b) CMV promoter from HPCs harvested at day of gene expression (day 2 after transduction), and (c) CMV promoter from HPCs harvested at day of gene silencing (day 7 after transduction). One circle corresponds to one cytosine in $\mathrm{CpG}$. The total number of cytosine in the CMV promoter is 36 . The filled circle corresponds to methylated $\mathrm{CpG}$ and the open circle corresponds to unmethylated $\mathrm{CpG}$.

In addition, the sequencing was performed in triplicate. These measures should improve the fidelity of the results.

Other literatures have shown that DNA methylation of promoter/enhancer region in oncoretroviral vectors was implicated in transgene silencing $[25,26]$. These results suggest that transgene silencing is initiated by DNA methylation at the promoter region. However, distinct methylation kinetics patterns were observed for the primer binding site and packaging signal regions, which were the CpG-rich regions. These $\mathrm{CpG}$-rich regions were hypermethylated as early as day 5 after transduction, even before the transgene has been silenced [4]. This report compliments our result, which shows that $\mathrm{CpG}$ in $\mathrm{CMV}$ promoter was methylated during the period of high transgene expression. Nevertheless, this confounding result will need further investigation.

3.8. Chromatin Immunoprecipitation Assay. Histone methylation can lead to transcriptionally active or inactive state of chromatin, depending on the amino acid residues being methylated [27]. Methylation of lysine 4 at the $\mathrm{H} 3$ tail has been associated with transcriptional active gene whereas 
methylation of lysine 9 at the $\mathrm{H} 3$ tail has been associated with transcription silencing [28-30]. Methylation of lysine 4 at $\mathrm{H} 3$ tail is a marker for euchromatin whereas methylation of lysine 9 at $\mathrm{H} 3$ tail is a typical code for heterochromatin in eukaryotic cells [4].

To further expand the analysis, the chromatin modifications in the CMV promoter and GFP reporter gene were examined. An open chromatin structure is often associated with histone $\mathrm{H} 3$ acetylation and active transcription. To examine whether the GFP silencing in HPCs transduced with LV was caused by the chromatin modifications, ChIP assay was performed on both the nonsilenced (day 2 after transduction) and the silenced (day 7 after transduction) HPCs. To determine whether there was histone code difference before and after transgene silencing, anti-H3 diMeK4 antibody and anti-H3 diMeK9 antibody were used in our study.

As a housekeeping gene, $\beta$-actin has an open chromatin structure under all conditions. Therefore, the $\beta$-actin promoter was used as a positive control in the ChIP assay. Based on the results obtained, $\beta$-actin promoter was enriched by anti-H3K9 antibody in both nonsilenced (Figures 8 (a) and $8(\mathrm{c})$ ) and silenced (Figures $8(\mathrm{~b})$ and $8(\mathrm{~d})$ ) transduced HPCs. In CMV promoter region, anti-H3K9 antibody was also enriched in both nonsilenced (Figure 8(a)) and silenced (Figure 8(b)) transduced HPCs. This suggests that the local $\mathrm{H} 3$ was in acetylated status before and after transgene silencing. CMV promoter region of the nonsilenced cells was enriched with anti-H3 diMeK4 antibody but not with antiH3 diMeK9 antibody (Figure 8(a)), a finding consistent with the euchromatic pattern in transcriptionally active region. However, for the silenced cells harvested at day 7 after transduction, both anti-H3 diMeK4 antibody and anti-H3 diMeK9 antibody were enriched in CMV promoter region (Figure 8(b)).

CMV promoter was enriched with both anti-H3K9 and anti-H3 diMeK4 antibodies at day 2 after transduction. Therefore, the histones in the region of the CMV promoter were in a euchromatic state at day 2 after transduction. This is consistent with the finding by $\mathrm{He}$ et al. [4]. For the murine embryonic carcinoma P19 cells transduced with the $\mathrm{LV}$, the EF1 $\alpha$ promoter was found to be in a euchromatin state in the positively expressed cells [4]. For the CMV promoter region extracted from HPCs harvested at day 7 after transduction (silenced cells), the histones were in a transition from euchromatin to heterochromatic state, since both anti$\mathrm{H} 3$ diMeK4 and anti-H3 diMeK9 antibodies were enriched.

The results obtained from the sodium bisulfite sequencing indicate that the CMV promoter was methylated at day 2 after transduction. However, the results obtained from ChIP assay indicates that the acetylation of histone still remained at similar day. He et al. [4] reported that the CpG methylation might not correlate with histone modifications because the packaging signal region in transcriptionally active state was quickly hypermethylated regardless of hyperacetylation status. Furthermore, euchromatin state of histones was still detected in our study. Therefore, we speculate that the CMV promoter region was in a transitional period from acetylated (euchromatin state) before being completely deacetylated (heterochromatin state).
After the chromatin status has been determined in the CMV promoter region in both nonsilenced and silenced cells, we examined the chromatin modifications in GFP reporter gene in the cells harvested at day 2 and day 7 after transduction. As shown in Figure 8(c), anti-H3K9 antibody was enriched in GFP gene of nonsilenced cells, which is consistent with the transcriptionally active state. This process could reduce the positive charge and weaken the interaction of histone with DNA, consequently, increasing the transcriptional activity. In contrast, no anti-H3K9 antibody was enriched in GFP reporter gene for the cells harvested at day 7 after transduction, in which the GFP expression declined (Figure $8(\mathrm{~d})$ ). The deacetylated histones could increase the positive charge of the histone and strengthen the interaction between histone and DNA. As the result, the entry and the binding of transcription factors to the region were inhibited.

Strangely, at day 2 after transduction, anti-H3 diMeK9 antibody was enriched in GFP gene but not anti-H3 diMeK4 (Figure 8(c)). This shows that although the GFP expression was high at day 2 after transduction, the GFP gene was in a heterochromatic state. Therefore, we speculate that although the region surrounding the GFP reporter gene is condensed, the GFP will still be expressed as long as the CMV promoter which controls the GFP expression is acetylated and is in a euchromatin state. At day 7 after transduction, anti-H3 diMeK9 was also enriched in GFP gene. This shows that GFP gene was in a heterochromatic state which is in agreement with a transcriptionally inactive period (Figure $8(\mathrm{~d})$ ). Overall, these results indicate that GFP reporter gene was in heterochromatic state at day 2 and day 7 after transduction even though GFP expression was detected at day 2 after transduction.

Table 2 summarizes our discoveries on the methylation and chromatin status of the CMV promoter and GFP transgene during the peak and lowest transgene expression from LV-transduced HPCs. The CMV promoter was found to be methylated at the very early stage of transgene expression, similar to the status at day 7 after transduction. As for the chromatin status, the CMV promoter was acetylated and was in euchromatic state at day of highest transgene expression and was acetylated and was in heterochromatic state at day of transgene silencing. Strangely, the GFP transgene was acetylated but was in heterochromatic state at day of highest transgene expression and was deacetylated and was in heterochromatic state at day of transgene silencing. These results suggest that the change in histone modifications in the promoter region correlates well with the initiation of transgene silencing. Our results support the study by $\mathrm{He}$ et al. [4] that transgene silencing is dominated by the status of the promoter.

\section{Conclusion}

Our study suggests that DNA methylation and dynamic histone modifications are involved in the transgene silencing of HPCs transduced by LV. The lentiviral expression vector without $\mathrm{CpG}$ is expected to be free from methylation; therefore, it is expected that there will be no recruitment of 


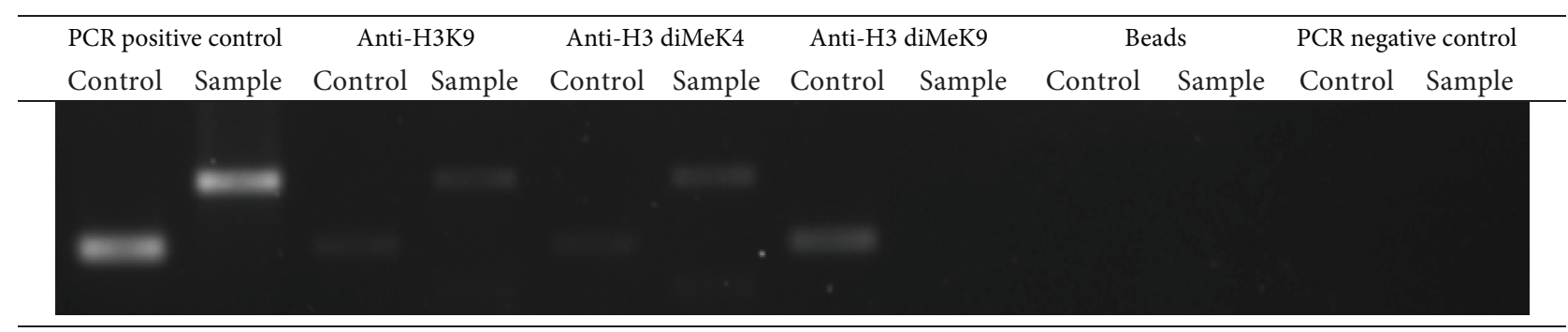

(a) CMV promoter region (At day 2 post-transduction)

\begin{tabular}{cccccccc}
\hline PCR positive control & Anti-H3K9 & Anti-H3 diMeK4 & Anti-H3 diMeK9 & \multicolumn{2}{c}{ Beads } & PCR negative control \\
Control Sample & Control Sample & Control Sample & Control Sample & Control Sample Control Sample \\
\hline & & - & & & & & \\
\hline
\end{tabular}

(b) CMV promoter region (At day 7 post-transduction)

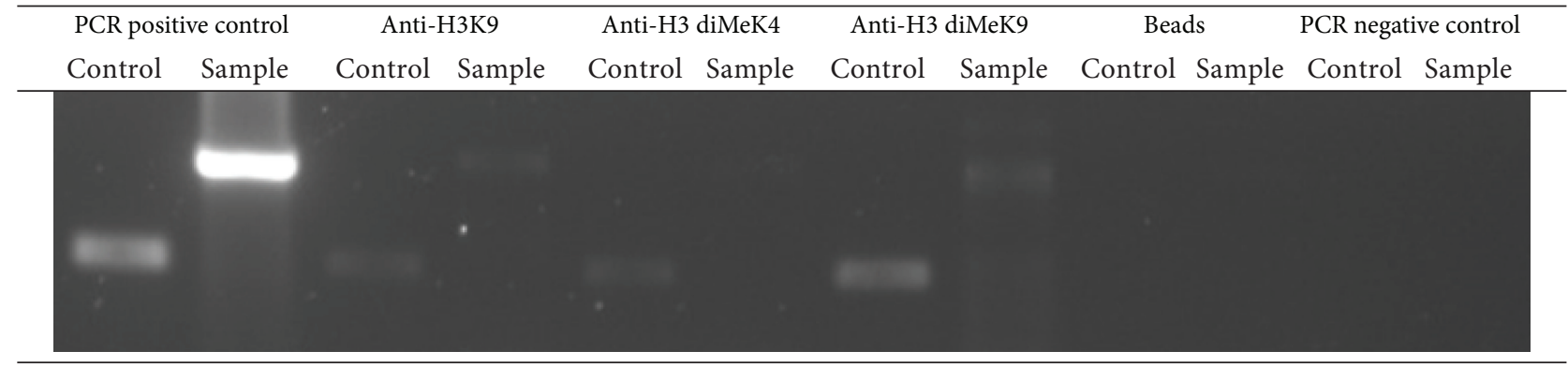

(c) GFP reporter gene (At day 2 post-transduction)

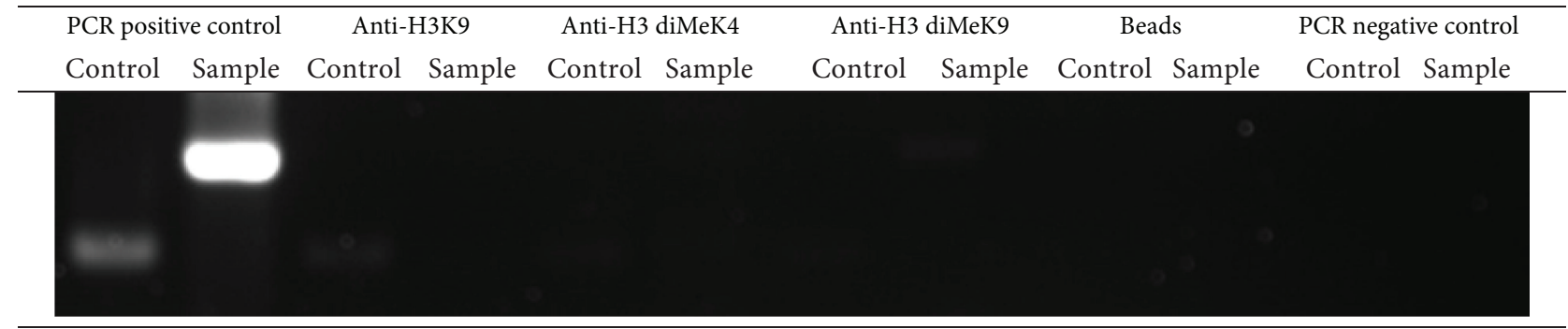

(d) GFP reporter gene (At day 7 post-transduction)

FIGURE 8: ChIP assay of CMV promoter region and GFP reporter gene at day 2 and day 7 post-transduction. The chromatin of the nonsilenced and silenced HPCs were harvested at day 2 and day 7 post-transduction and immunoprecipitated with anti-histone $\mathrm{H} 3$ acetyl lysine 9 (Anti-H3K9) antibody, anti-histone H3 dimethyl lysine 4 (Anti-H3 diMeK4) antibody and anti-histone H3 dimethyl lysine 9 (Anti-H3 diMeK9) antibody. The DNA was subjected to PCR with primers specific to either CMV promoter region or GFP reporter gene and $\beta$-actin promoter region (As positive control for ChIP assay). The chromatin harvested without immunoprecipitation (Beads) was set as a negative control for the ChIP assay. The PCR reaction mixture without DNA was set as the negative control for PCR.

transcriptional repressor complexes to silent the gene expression. Boundary elements or insulators can also be inserted in the lentiviral construct to prevent the encroachment of heterochromatin into the promoter and/or transgene region. It is hoped that with these proposed strategies, the transgene silencing problems in HPCs transduced with LV could be solved and long-term therapeutic gene expression could be achieved.

\section{Conflict of Interests}

There is no conflict of interests regarding the publication of this paper.

\section{Authors' Contribution}

Siew Ching Ngai and Syahril Abdullah are equal contributors. 
TABLE 2: Summary on the methylation and chromatin status of the CMV promoter and GFP transgene during the lowest and the highest GFP expression.

(a)

\begin{tabular}{lcr}
\hline Day 2 & CMV Promoter & GFP Transgene \\
Highest GFP Expression & Acetylated/Euchromatic & Acetylated/Heterochromatic \\
\hline Chromatin Status & Methylated & \\
Methylation status & & \\
\hline
\end{tabular}

(b)

\begin{tabular}{lcc}
\hline $\begin{array}{l}\text { Day } 7 \\
\text { Lowest GFP Expression }\end{array}$ & CMV Promoter & GFP Transgene \\
\hline Chromatin Status & Acetylated/Heterochromatic & Deacetylated/Heterochromatic \\
Methylation status & Methylated & \\
\hline
\end{tabular}

\section{Acknowledgments}

This work was supported by grant from Ministry of Science, Technology and Innovation, Malaysia (Science Fund: 02-0104-SF0230) and Research University Grant Scheme, Universiti Putra Malaysia (04-04-10-1028RU).

\section{References}

[1] D. Escors and K. Breckpot, "Lentiviral vectors in gene therapy: their current status and future potential," Archivum Immunologiae et Therapiae Experimentalis, vol. 58, no. 2, pp. 107-119, 2010.

[2] D. Nevozhay and A. Opolski, "Key factors in experimental mouse hematopoietic stem cell transplantation," Archivum Immunologiae et Therapiae Experimentalis, vol. 54, no. 4, pp. 253-269, 2006.

[3] N.-B. Woods, A. Ooka, and S. Karlsson, "Development of gene therapy for hematopoietic stem cells using lentiviral vectors," Leukemia, vol. 16, no. 4, pp. 563-659, 2002.

[4] J. He, Q. Yang, and L.-J. Chang, "Dynamic DNA methylation and histone modifications contribute to lentiviral transgene silencing in murine embryonic carcinoma cells," Journal of Virology, vol. 79, no. 21, pp. 13497-13508, 2005.

[5] J. N. Ou, J. Torrisani, A. Unterberger et al., "Histone deacetylase inhibitor Trichostatin A induces global and gene-specific DNA demethylation in human cancer cell lines," Biochemical Pharmacology, vol. 73, no. 9, pp. 1297-1307, 2007.

[6] C. P. Hong, M. K. Choe, and T.-Y. Roh, "Characterization of chromatin structure-associated histone modifications in breast cancer cells," Genomics \& Informatics, vol. 10, no. 3, pp. 145-152, 2012.

[7] W. Y. Chen and T. M. Townes, "Molecular mechanism for silencing virally transduced genes involves histone deacetylation and chromatin condensation," Proceedings of the National Academy of Sciences of the United States of America, vol. 97, no. 1, pp. 377$382,2000$.

[8] M. J. Barter, C. Bui, and D. A. Young, "Epigenetic mechanisms in cartilage and osteoarthritis: DNA methylation, histone modifications and microRNAs," Osteoarthritis and Cartilage, vol. 20, no. 5, pp. 339-349, 2012.

[9] T. Vaissière, C. Sawan, and Z. Herceg, "Epigenetic interplay between histone modifications and DNA methylation in gene silencing," Mutation Research, vol. 659, no. 1-2, pp. 40-48, 2008.
[10] A. W. Wognum, A. C. Eaves, and T. E. Thomas, "Identification and isolation of hematopoietic stem cells," Archives of Medical Research, vol. 34, no. 6, pp. 461-475, 2003.

[11] H. Ema, Y. Morita, and H. Nakauchi, "Phenotype of mouse hematopoietic stem cells," in Handbook of Stem Cells, R. Lanza, H. Blau, D. Melton et al., Eds., pp. 323-327, Elsevier Academic Press, New York, NY, USA, 2004.

[12] G. J. Spangrude and D. M. Brooks, "Mouse strain variability in the expression of the hematopoietic stem cell antigen Ly-6A/E by bone marrow cells," Blood, vol. 82, no. 11, pp. 3327-3332, 1993.

[13] Y. Ma, A. Ramezani, R. Lewis, R. G. Hawley, and J. A. Thomson, "High-level sustained transgene expression in human embryonic stem cells using lentiviral vectors," Stem Cells, vol. 21, no. 1, pp. 111-117, 2003.

[14] S. Hino, J. Fan, S. Taguwa, K. Akasaka, and M. Matsuoka, "Sea urchin insulator protects lentiviral vector from silencing by maintaining active chromatin structure," Gene Therapy, vol. 11, no. 10, pp. 819-828, 2004.

[15] N. S. Yew, M. Przybylska, R. J. Ziegler, D. Liu, and S. H. Cheng, "High and sustained transgene expression in vivo from plasmid vectors containing a hybrid ubiquitin promoter," Molecular Therapy, vol. 4, no. 1, pp. 75-82, 2001.

[16] L. Qin, Y. Ding, D. R. Pahud, E. Chang, M. J. Imperiale, and J. S. Bromberg, "Promoter attenuation in gene therapy: interferon$\gamma$ and tumor necrosis factor- $\alpha$ inhibit transgene expression," Human Gene Therapy, vol. 8, no. 17, pp. 2019-2029, 1997.

[17] G. Escher, A. Hoang, S. Georges et al., "Demethylation using the epigenetic modifier, 5-azacytidine, increases the efficiency of transient transfection of macrophages," The Journal of Lipid Research, vol. 46, no. 2, pp. 356-365, 2005.

[18] M. Di Ianni, A. Terenzi, K. Perruccio et al., "5-Azacytidine prevents transgene methylation in vivo," Gene Therapy, vol. 6, no. 4, pp. 703-707, 1999.

[19] D. V. Santi, C. E. Garrett, and P. J. Barr, "On the mechanism of inhibition of DNA-cytosine methyltransferases by cytosine analogs," Cell, vol. 33, no. 1, pp. 9-10, 1983.

[20] Q. J. Lu and B. Richardson, "Methods for analyzing the role of DNA methylation and chromatin structure in regulating $\mathrm{T}$ lymphocyte gene expression," Biological Procedures Online, vol. 6, no. 1, pp. 189-203, 2004.

[21] B. D. Strahl and C. D. Allis, "The language of covalent histone modifications," Nature, vol. 403, no. 6765, pp. 41-45, 2000.

[22] X. Nan, H.-H. Ng, C. A. Johnson et al., "Transcriptional repression by the methyl-CpG-binding protein $\mathrm{MeCP} 2$ involves 
a histone deacetylase complex," Nature, vol. 393, no. 6683, pp. 386-389, 1998.

[23] E. E. Cameron, K. E. Bachman, S. Myöhänen, J. G. Herman, and S. B. Baylin, "Synergy of demethylation and histone deacetylase inhibition in the re-expression of genes silenced in cancer," Nature Genetics, vol. 21, no. 1, pp. 103-107, 1999.

[24] A.-N. Ma, J. Lu, X.-J. Zhou, and Y.-X. Wang, "Histone deacetylation directs DNA methylation in surviving gene silencing," Biochemical and Biophysical Research Communications, vol. 404, no. 1, pp. 268-272, 2011.

[25] S. R. Cherry, D. Biniszkiewicz, L. van Parijs, D. Baltimore, and R. Jaenisch, "Retroviral expression in embryonic stem cells and hematopoietic stem cells," Molecular and Cellular Biology, vol. 20, no. 20, pp. 7419-7426, 2000.

[26] P.-M. Challita, D. Skelton, A. El-Khoueiry, X.-J. Yu, K. Weinberg, and D. B. Kohn, "Multiple modifications in cis elements of the long terminal repeat of retroviral vectors lead to increased expression and decreased DNA methylation in embryonic carcinoma cells," Journal of Virology, vol. 69, no. 2, pp. 748-755, 1995.

[27] D. P. Gavin and R. P. Sharma, "Histone modifications, DNA methylation and Schizophrenia," Neuroscience and Biobehavioral Reviews, vol. 34, no. 6, pp. 882-888, 2010.

[28] C. L. Peterson and M. A. Laniel, "Histones and histone modifications," Current Biology, vol. 14, pp. R546-R551, 2004.

[29] T. Jenuwein and C. D. Allis, "Translating the histone code," Science, vol. 293, no. 5532, pp. 1074-1080, 2001.

[30] Y. Zhang and D. Reinberg, "Transcription regulation by histone methylation: interplay between different covalent modifications of the core histone tails," Genes and Development, vol. 15, no. 18, pp. 2343-2360, 2001. 

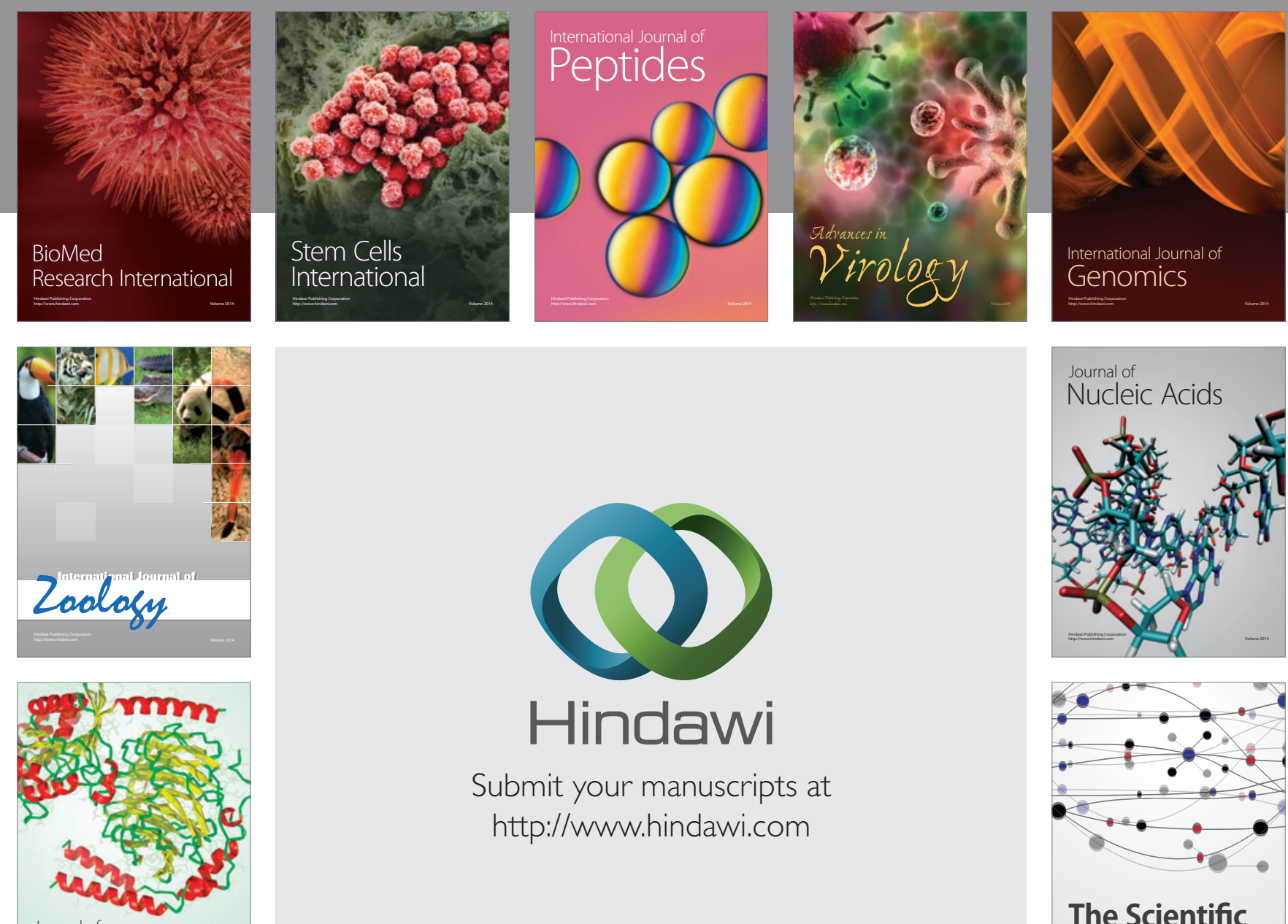

Submit your manuscripts at

http://www.hindawi.com

Journal of
Signal Transduction
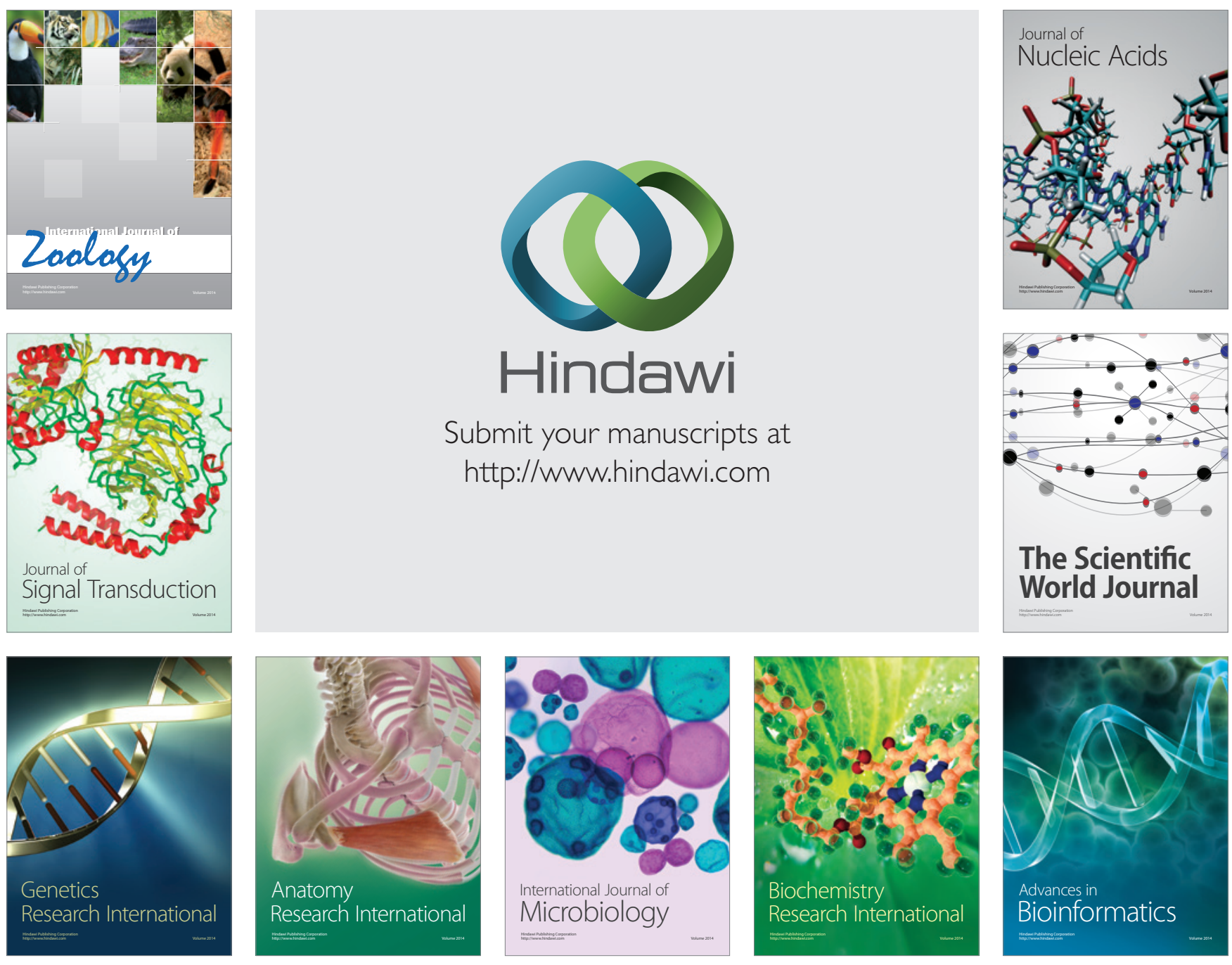

The Scientific World Journal
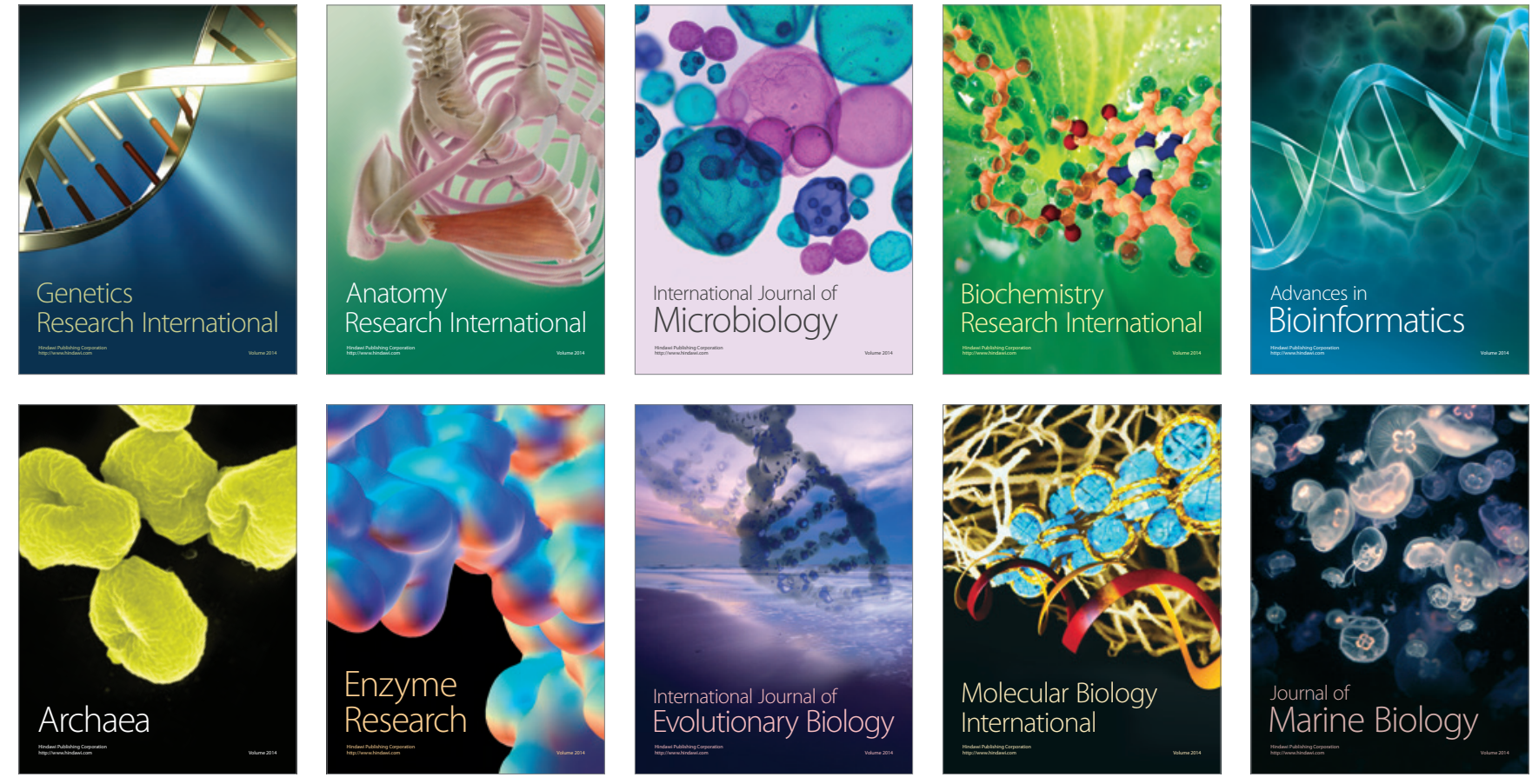